OPEN ACCESS

Edited by:

Sai Gautam Gopalakrishnan, Princeton University, United States

Reviewed by:

Yushi He,

Shanghai Jiao Tong University, China

Bora Karasulu,

University of Cambridge,

United Kingdom

*Correspondence:

Masaki Matsu

matsui@godzilla.kobe-u.ac.jp

Specialty section:

This article was submitted to

Inorganic Chemistry,

a section of the journal

Frontiers in Chemistry

Received: 17 October 2018

Accepted: 07 January 2019

Published: 23 January 2019

Citation:

Matsui M, Kuwata H, Mori D, Imanishi N and Mizuhata M (2019)

Destabilized Passivation Layer on Magnesium-Based Intermetallics as Potential Anode Active Materials for

Magnesium lon Batteries.

Front. Chem. 7:7.

doi: 10.3389/fchem.2019.00007

\section{Destabilized Passivation Layer on Magnesium-Based Intermetallics as Potential Anode Active Materials for Magnesium Ion Batteries}

\author{
Masaki Matsui ${ }^{1 *}$, Hiroko Kuwata ${ }^{2}$, Daisuke Mori ${ }^{2}$, Nobuyuki Imanishi ${ }^{2}$ and \\ Minoru Mizuhata ${ }^{1}$ \\ ${ }^{1}$ Department of Chemical Science and Engineering, Kobe University, Kobe, Japan, ${ }^{2}$ Department of Chemistry for \\ Materials, Mie University, Tsu, Japan
}

Passivation of magnesium metal anode is one of the critical challenges for the development of magnesium batteries. Here we investigated the passivation process of an intermetallic anode: $\mathrm{Mg}_{3} \mathrm{Bi}_{2}$ synthesized by solid-state and thin film process. The $\mathrm{Mg}_{3} \mathrm{Bi}_{2}$ composite electrode shows excellent reversibility in magnesium bis(trifluoromethansulfonylamide) dissolved in acetonitrile, while $\mathrm{Mg}_{3} \mathrm{Sb}_{2}$, which has same crystal structure and similar chemical properties, is electrochemically inactive. We also fabricated the $\mathrm{Mg}_{3} \mathrm{Bi}_{2}$ thin film electrodes, which show reversibility with low overpotential not only in the acetonitrile solution but also glyme-based solutions. Surface layer corresponding to the decomposed TFSA anion is slightly suppressed in the case of the $\mathrm{Mg}_{3} \mathrm{Bi}_{2}$ thin film electrode, compared with $\mathrm{Mg}$ metal. Comparative study of hydrolysis process of the $\mathrm{Mg}_{3} \mathrm{Bi}_{2}$ and the $\mathrm{Mg}_{3} \mathrm{Sb}_{2}$ suggests that the both intermetallic anodes are not completely passivated. The bond valence sum mapping of the $\mathrm{Mg}_{3} \mathrm{Bi}_{2}$ indicates that the fast $\mathrm{Mg}^{2+}$ diffusion pathway between $2 d$ tetrahedral sites is formed. The electrochemical properties of the $\mathrm{Mg}_{3} \mathrm{Bi}_{2}$ anode is mainly due to the less passivation surface with the fast $\mathrm{Mg}^{2+}$ diffusion pathways.

Keywords: intermetallics, anode, passivation layer, hydrolysis, bond-valence sum mapping, $\mathrm{Mg}^{2+}$ diffusion pathway

\section{INTRODUCTION}

Beyond Li-ion batteries have been widely investigated last decade (Larcher and Tarascon, 2015). Alternative anode active material using electrochemical deposition-dissolution process of less-noble metal is one strategy for the development of high-energy battery system (Lin et al., 2017). Among various choices of the less-noble metal anodes, magnesium is one of the potential candidates as the high-energy anode active material, because the volumetric capacity: 3,800 mAh $\mathrm{cm}^{-3}$ is 1.9 times higher than that of lithium metal, and no dendritic growth during the deposition process (Matsui, 2011). On the other hand, the surface of the magnesium metal is easily passivated in conventional electrolyte solutions such as magnesium perchlorate dissolved in propylene carbonate (Lu et al., 1999). Therefore, the choice of the electrolyte solutions for rechargeable magnesium batteries is very limited. Typically the organohaloaluminate electrolyte solutions, which are widely studied by Aurbach et al. in early 2000s (e.g., Aurbach et al., 2000, 2003, 2007), 
show highly reversible deposition/dissolution of magnesium metal, however since these electrolyte solutions contain halides: $\mathrm{Cl}^{-}$or $\mathrm{Br}^{-}$, the potential window of the organohaloaluminate electrolyte solutions is limited. In addition the corrosive properties of the halides initiate the dissolution of the cathode current collector at high cell voltage $>2.5 \mathrm{~V}$ (Muldoon et al., 2012). Therefore, finding halide-free electrolyte solutions has been standing in the center of the electrolyte development for high-voltage magnesium batteries. Recently, Tutusaus et al. reported a new class of the magnesium salt having boron cluster anion monocarborane $\mathrm{CB}_{11} \mathrm{H}_{12^{-}}$dissolved in glymes showed reversible deposition/dissolution of magnesium without corrosive properties (Tutusaus et al., 2015). A fluorinated alkokyborate-based electrolyte: magnesium hexafluoroisopropylaluminate $\left(\mathrm{Mg}\left[\mathrm{B}(\mathrm{hfip})_{4}\right]_{2}\right)$ also shows excellent reversibility without the corrosive properties (ZhaoKarger et al., 2017). Even with the excellent electrochemical properties of these new class of the electrolytes, the oxidation stabilities of these solutions are still limited up to $3.5 \mathrm{~V}$ vs. $\mathrm{Mg}$ due to the ether-based solvents.

Our group has been working on intermetallic anodes such as $\mathrm{Mg}_{3} \mathrm{Bi}_{2}$ and $\mathrm{Mg}_{2} \mathrm{Sn}$, because the intermetallic anodes are compatible with a conventional electrolyte solution: magnesium bis(trifluoromethansulfonylamide) $\left(\mathrm{Mg}(\mathrm{TFSA})_{2}\right)$ dissolved in acetonitrile(AN) (Arthur et al., 2012; Singh et al., 2013). Despite the high equilibrium potential and the low specific capacity of the $\mathrm{Mg}_{3} \mathrm{Bi}_{2}$, the compatibility against wide variety of the electrolyte solutions could become an advantage for the development of a battery system. Moreover, since the bismuth is very heavy element, the volumetric capacity of the $\mathrm{Mg}_{3} \mathrm{Bi}_{2}$ : $1906 \mathrm{mAh}$ $\mathrm{cm}^{-3}$ is still comparable value to the theoretical capacity of lithium metal. Therefore, we think the "Mg-ion" battery using the intermetallic anode could be a more realistic direction to develop a practical battery system.

Even with the several reports concerning the $\mathrm{Mg}_{3} \mathrm{Bi}_{2}$ as the anode active material for $\mathrm{Mg}$-ion batteries, there still remains room to understand why the $\mathrm{Mg}_{3} \mathrm{Bi}_{2}$ shows the compatibility with various electrolytes solutions. Also the fast reaction kinetics of the $\mathrm{Mg}_{3} \mathrm{Bi}_{2}$ among various $\mathrm{Mg}$-based intermetallic anodes, are still under investigation. In the present study, we attempted to understand the origin of the wide compatibility and the fast kinetics of the $\mathrm{Mg}_{3} \mathrm{Bi}_{2}$ as the alternate anode active material for magnesium batteries. We investigated the electrochemical properties of the $\mathrm{Mg}_{3} \mathrm{Bi}_{2}$ composite electrodes, synthesized by a conventional solid-state process. In order to conduct comparative studies, another intermetallic anode: $\mathrm{Mg}_{3} \mathrm{Sb}_{2}$ was also investigated, because of its structural and chemical similarities to the $\mathrm{Mg}_{3} \mathrm{Bi}_{2}$. The $\mathrm{Mg}_{3} \mathrm{Sb}_{2}$ has same crystal structure to the $\mathrm{Mg}_{3} \mathrm{Bi}_{2}$, in both magnesiated and demagnesiated phases. In addition the binary phase diagram of $\mathrm{Mg}$-Sb system shows that the expected electrochemical reaction is a two-phase reaction of $\mathrm{Mg}_{3} \mathrm{Sb}_{2}$ and $\mathrm{Sb}$, which is exact same as the two phase reaction in the $\mathrm{Mg}$-Bi system. We also fabricated $\mathrm{Mg}$ metal and $\mathrm{Mg}_{3} \mathrm{Bi}_{2}$ thin film electrodes using rf-sputtering coater to investigate the correlation between the surface layer and the overpotential of the magnesium metal and the $\mathrm{Mg}_{3} \mathrm{Bi}_{2}$. The surface layer on the magnesium metal and the $\mathrm{Mg}_{3} \mathrm{Bi}_{2}$ thin films were characterized using X-ray photoelectron spectroscopy (XPS). In order to evaluate the stability of the surface layer on the intermetallic anodes, the hydrolysis process of the $\mathrm{Mg}_{3} \mathrm{Bi}_{2}$ and the $\mathrm{Mg}_{3} \mathrm{Sb}_{2}$ were investigated. The $\mathrm{Mg}^{2+}$ diffusion pathways in the $\mathrm{Mg}_{3} \mathrm{Bi}_{2}$ and the $\mathrm{Mg}_{3} \mathrm{Sb}_{2}$ were estimated by bond-valence sum (BVS) mapping (Adams, 2006) to discuss the reaction kinetics of these two intermetallic anodes.

\section{MATERIALS AND METHODS \\ Synthesis and Characterization}

The $\mathrm{Mg}_{3} \mathrm{Bi}_{2}$ and the $\mathrm{Mg}_{3} \mathrm{Sb}_{2}$ powders were synthesized by a conventional solid-state reaction from stoichiometric amount of magnesium powder (99.8\%, Alfa Aesar) and bismuth powder (99.999\%, Alfa Aesar) or antimony powder (99.999\%, Alfa Aesar) with $10 \%$ excess magnesium. The metal powders were thoroughly mixed using an agate mortar and pestle. Subsequently the mixture of the materials were mechanically milled using a planetary ball mill (PL-7, Fritsch) with $\mathrm{ZrO}_{2}$ grinding bowls and balls, for $8 \mathrm{~h}$ at $400 \mathrm{rpm}$. The milled powders were pressed into pellets and calcined at $550^{\circ} \mathrm{C}$ for $5 \mathrm{~h}$ to obtain the single phase of the intermetallics. The calcined pellets were ground and sieved before the preparation of the electrode slurry. In order to avoid the oxidation of the materials, all the synthesis procedures were carried out under inert atmosphere.

The $\mathrm{Mg}_{3} \mathrm{Bi}_{2}$ and the magnesium metal thin films were also fabricated to characterize the passivation layer. The thin film fabrication was carried out using a magnetron sputtering coater (Pascal) equipped with $2^{\prime \prime}$ of magnesium and bismuth target. Since the load-lock is directly connected to the argon-filled glove box, the thin films can be prepared without air exposure. We employed a copper foil as substrate of the thin film electrode. The native oxide layer of the copper substrate was removed by sputter etching at $20 \mathrm{~W}$ for $20 \mathrm{~min}$. The $\mathrm{Mg}_{3} \mathrm{Bi}_{2}$ thin films were fabricated by co-sputtering process of magnesium and bismuth. The rf power was 50 and $20 \mathrm{~W}$ for the magnesium and the bismuth respectively. The sputtering duration was $15 \mathrm{~min}$. The substrate was heated at $200^{\circ} \mathrm{C}$ and rotated at $10 \mathrm{rpm}$ to obtain uniform coatings. Thin films of the magnesium metal were also fabricated almost same sputtering condition above. The sputtering duration is increased to $20 \mathrm{~min}$ without the sputtering of the bismuth. The thickness of the $\mathrm{Mg}_{3} \mathrm{Bi}_{2}$ thin film is $\approx 500 \mathrm{~nm}$.

The synthesized powders and the thin films were characterized using X-ray diffractometer (D8 ADVANCE, Bruker) equipped with $\mathrm{Cu}-\mathrm{K} \alpha$ radiation. The sample preparation was carried out in the argon-filled glove box $<1.0 \mathrm{ppm}$ of moisture and oxygen, using an airtight sample holder to avoid the air exposure of the samples during the measurement. The structural refinement for the powder samples was carried out using RIERAN-FP ver. 2.84 (Izumi and Momma, 2007) and the crystal structures were drawn by VESTA 3.4.4 (Momma and Izumi, 2011). We also performed the BVS mapping to visualize the $\mathrm{Mg}^{2+}$ ion diffusion pathways, using PyAbstantia ver. 0.7 (Nishimura, 2017).

\section{Electrochemistry}

The electrode slurry was prepared by mixing the $80 \mathrm{wt} \%$ of the $\mathrm{Mg}_{3} \mathrm{Bi}_{2}$ or $\mathrm{Mg}_{3} \mathrm{Sb}_{2}$ powder, $10 \mathrm{wt} \%$ of acetylene black (TIMCAL), 
and $10 \mathrm{wt} \%$ of polyimide binder (Toray) dissolved in anhydrous NMP. The mixed slurry was coated on the copper foil and dried at $80^{\circ} \mathrm{C}$ under vacuum and pressed. Subsequently the electrode were heated at $350^{\circ} \mathrm{C}$ under argon flow for the thermal imidization of the binder. The loading level of the $\mathrm{Mg}_{3} \mathrm{Bi}_{2}$ and $\mathrm{Mg}_{3} \mathrm{Sb}_{2}$ are within the range $2.8-3.3 \mathrm{mg} \mathrm{cm}{ }^{-2}$. The $\mathrm{Mg}_{3} \mathrm{Bi}_{2}$ thin film electrodes were used without further treatment.

Conventional three-electrode cells were employed for the electrochemical measurement. The composite/thin film electrodes were used as the working electrodes. The counter electrode was a platinum or magnesium foil. The reference electrode had a silver wire immersed in $0.05 \mathrm{~mol} \mathrm{~L} \mathrm{~L}^{-1} \mathrm{AgNO}_{3}$ (Wako) in acetonitrile: $\mathrm{AN}$ (Kishida) solution with two liquid junctions with microporous glass membranes to avoid contamination of the $\mathrm{Ag}^{+}$ion into the electrolyte solution. A $1.0 \mathrm{~mol} \mathrm{~L}^{-1}$ magnesium bis(trifluoromethanesulfonyl)amide: $\mathrm{Mg}(\mathrm{TFSA})_{2}$ in $\mathrm{AN}$ solution
(Kishida) was used as the electrolyte solution. We also prepared glyme-based electrolyte solutions. The $\mathrm{Mg}(\mathrm{TFSA})_{2}$ salt (Kishida) was vacuum dried at $170^{\circ} \mathrm{C}$ for $8 \mathrm{~h}$. The glyme-based solvents monoglyme: G1 (Kishida) and butylmethyltriglyme:BuMeG3 (Wako) were dried over activated molecular sieve (5A) for $36 \mathrm{~h}$ until the water content reaches $<15 \mathrm{ppm}$. Subsequently the $\mathrm{Mg}(\mathrm{TFSA})_{2}$ was dissolved in the solvents to use as the electrolyte solutions. The water content of the solvents and solutions were measured by Karl Fischer titration method (Mitsubishi Chemical Analytics).

\section{Surface Analysis}

In order to characterize the passivation layer at the surface of the $\mathrm{Mg}_{3} \mathrm{Bi}_{2}$ thin film electrode, we conducted X-ray photo electron spectroscopy: XPS (ESCA3400, Shimadzu) with $\mathrm{Mg}-\mathrm{K} \alpha$ radiation. As a comparison, the XPS spectra for a magnesium metal thin film was also measured. The $\mathrm{Mg}_{3} \mathrm{Bi}_{2}$ and the
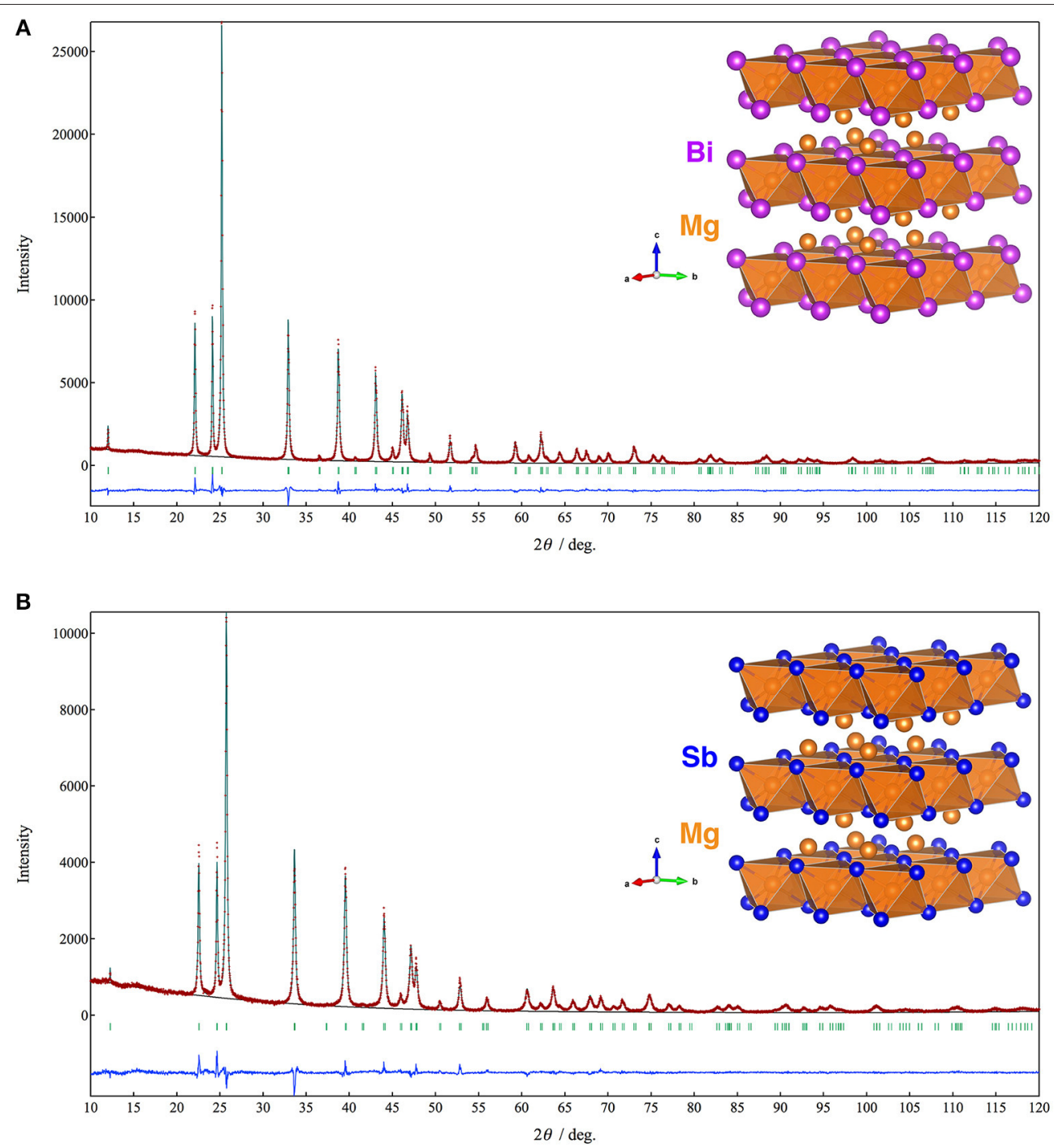

FIGURE 1 | Powder XRD patterns and the crystal structures of (A) $\mathrm{Mg}_{3} \mathrm{Bi}_{2}$ and (B) $\mathrm{Mg}_{3} \mathrm{Sb}_{2}$. The brown symbols are measured value of the PXRD data, the dark green line is the simulated pattern. The light green marks represents the peak positions and the blue line is corresponding to the residue. 
TABLE 1 | Rietveld refinement result of $\mathrm{Mg}_{3} \mathrm{Bi}_{2}$.

\begin{tabular}{|c|c|c|c|c|c|c|}
\hline \multicolumn{7}{|c|}{ (A) Crystallographic Data of $\mathrm{Mg}_{3} \mathrm{Bi}_{2}$} \\
\hline \multicolumn{4}{|c|}{ Crystal system, Space group } & \multicolumn{3}{|c|}{ Trigonal, $P \overline{3} m 1$ (No. 164) } \\
\hline \multicolumn{4}{|l|}{$a / \AA ̊$} & \multicolumn{3}{|c|}{$4.65349(5)$} \\
\hline \multicolumn{4}{|l|}{$c / \AA ̊$} & \multicolumn{3}{|c|}{$7.38997(9)$} \\
\hline \multicolumn{4}{|c|}{ Cell volume $/ \AA^{3}$} & \multicolumn{3}{|c|}{ 138.5899(28) } \\
\hline \multicolumn{4}{|l|}{$R_{w p}$} & \multicolumn{3}{|c|}{6.190} \\
\hline \multicolumn{4}{|l|}{$R_{p}$} & \multicolumn{3}{|c|}{4.746} \\
\hline \multicolumn{4}{|l|}{ GoF } & \multicolumn{3}{|c|}{1.4560} \\
\hline \multicolumn{4}{|l|}{$R_{\mathrm{b}}$} & \multicolumn{3}{|c|}{1.567} \\
\hline \multicolumn{7}{|c|}{$\begin{array}{l}\text { (B) Fractional Atomic Coordinates, Occupancies and } \\
\text { Isotropic Displacement }\end{array}$} \\
\hline Site & Wyckoff & $x$ & $y$ & $z$ & occ. & $B(\AA ̊)$ \\
\hline$M g(1)$ & $1 a$ & 0 & 0 & 0 & 1 & 1.5 \\
\hline $\mathrm{Mg}(2)$ & $2 d$ & 0.33333 & 0.66667 & $0.63187(61)$ & 1 & 1.5 \\
\hline $\mathrm{Bi}(1)$ & $2 d$ & 0.33333 & 0.66667 & $0.22473(10)$ & 1 & 0.9 \\
\hline
\end{tabular}

magnesium metal thin films were immersed in the BuMeG3 solution for $24 \mathrm{~h}$, right after the sputtering process. Subsequently the thin films were rinsed with monoglyme(G1) to remove the BuMeG3 solutions. The emission current and the acceleration voltatge of the X-ray gun is $20 \mathrm{~mA}$ and $10 \mathrm{kV}$ respectively. Argon ion etching, with $20 \mathrm{~mA}$ of emission current and $2 \mathrm{kV}$ of acceleration voltage, was carried out to take the depth profile.

\section{RESULTS AND DISCUSSIONS}

\section{Electrochemical Properties of the $\mathrm{Mg}_{3} \mathrm{Bi}_{2}$ and $\mathrm{Mg}_{3} \mathrm{Sb}_{2}$ Composite Electrode}

Figure 1 shows XRD patterns and Rietveld refinement results of the $\mathrm{Mg}_{3} \mathrm{Bi}_{2}$ and $\mathrm{Mg}_{3} \mathrm{Sb}_{2}$. Both of the diffraction patterns are assigned to A-type rare earth structure with trigonal $P \overline{3} m 1$ space group. The refinement yields the trigonal lattice with $a$ $=4.65349(5) \AA$ and $c=7.38997(9) \AA$ for $\mathrm{Mg}_{3} \mathrm{Bi}_{2}$ and $a=$ 4.55963(10) $\AA$ and $c=7.22933 \AA$ for $\mathrm{Mg}_{3} \mathrm{Sb}_{2}$ respectively. The magnesium occupies $1 a$ site and half of $2 d$ sites. The bismuth or antimony occupies another half of $2 d$ sites. Both refinement results are in good agreement with reported data (Ahmadpour et al., 2007; Liu et al., 2017). Summary of the refinement results are shown in Tables 1, 2. The crystal structure of both the $\mathrm{Mg}_{3} \mathrm{Bi}_{2}$ and the $\mathrm{Mg}_{3} \mathrm{Sb}_{2}$ can be described as a layered structure of hexagonal close-packed (h.c.p) bismuth array with $\mathrm{Mg}$ atoms located at the octahedral voids in every two bismuth c.p. layers, and the tetrahedral voids in the another two bismuth c.p. layers.

Even though the crystal structures of the $\mathrm{Mg}_{3} \mathrm{Bi}_{2}$ and the $\mathrm{Mg}_{3} \mathrm{Sb}_{2}$ are very similar except the slight difference of the lattice constants, the electrochemical properties of these two compounds are significantly different. The cyclic voltammograms of the $\mathrm{Mg}_{3} \mathrm{Bi}_{2}$ and the $\mathrm{Mg}_{3} \mathrm{Sb}_{2}$ composite electrodes in $1.0 \mathrm{~mol} \mathrm{~L} \mathrm{~L}^{-1} \mathrm{Mg}(\mathrm{TFSA})_{2}$ in $\mathrm{AN}$ solution, overlapped with a cyclic voltammogram of the deposition/dissolution process of magnesium metal in $0.5 \mathrm{~mol}$
TABLE 2 | Rietveld refinement result of $\mathrm{Mg}_{3} \mathrm{Sb}_{2}$.

\begin{tabular}{|c|c|c|c|c|c|c|}
\hline \multicolumn{7}{|c|}{ (A) Crystallographic Data of $\mathrm{Mg}_{3} \mathrm{Sb}_{2}$} \\
\hline \multicolumn{4}{|c|}{ Crystal system, Space group } & \multicolumn{3}{|c|}{ Trigonal, $P \overline{3} m 1$ (No. 164) } \\
\hline \multicolumn{4}{|l|}{$a / \AA ̊$} & \multicolumn{3}{|c|}{$4.55963(10)$} \\
\hline \multicolumn{4}{|l|}{$c / \AA$} & \multicolumn{3}{|c|}{$7.22933(16)$} \\
\hline \multicolumn{4}{|c|}{ Cell volume $/ \AA^{3}$} & \multicolumn{3}{|c|}{$130.1629(51)$} \\
\hline \multicolumn{4}{|l|}{$R_{\mathrm{wp}}$} & \multicolumn{3}{|c|}{7.155} \\
\hline \multicolumn{4}{|l|}{$R_{p}$} & \multicolumn{3}{|c|}{5.501} \\
\hline \multicolumn{4}{|l|}{ GoF } & \multicolumn{3}{|c|}{1.8635} \\
\hline \multicolumn{4}{|l|}{$R_{\mathrm{b}}$} & \multicolumn{3}{|c|}{1.906} \\
\hline \multicolumn{7}{|c|}{$\begin{array}{l}\text { (B) Fractional Atomic Coordinates, Occupancies, and Isotropic } \\
\text { Displacement }\end{array}$} \\
\hline Site & Wyckoff & $x$ & $y$ & $z$ & occ. & $B(\AA)$ \\
\hline $\operatorname{Mg}(1)$ & $1 a$ & 0 & 0 & 0 & 1 & 1.2 \\
\hline $\operatorname{Mg}(2)$ & $2 d$ & 0.33333 & 0.66667 & $0.63501(51)$ & 1 & 1.2 \\
\hline $\mathrm{Bi}(1)$ & $2 d$ & 0.33333 & 0.66667 & $0.22979(15)$ & 1 & 0.9 \\
\hline
\end{tabular}

$\mathrm{L}^{-1} \mathrm{Mg}(\mathrm{TFSA})_{2}$ in BuMeG3 solution, are shown in Figure 2. The $\mathrm{Mg}_{3} \mathrm{Bi}_{2}$ shows very sharp reversible peaks corresponding to demagnetization/magnetization process at $-2.1 \mathrm{~V}$ vs. $\mathrm{Ag}^{+} / \mathrm{Ag}$. Even though the sweep rate of the cyclic voltammogram is faster than reported data, the overpotential between the anodic and cathodic reaction is almost same as previous one: $\sim 80 \mathrm{mV}$. It suggests that the overpotential is not corresponding to the reaction kinetics, but thermodynamic properties, such as solvation/desolvation energy or phase transition of the solid phase. In addition, the overpotential of the $\mathrm{Mg}_{3} \mathrm{Bi}_{2}$ is much lower than that of the deposition/dissolution process of the magnesium in the BuMeG3 solution. Hence the $\mathrm{Mg}_{3} \mathrm{Bi}_{2}$ obviously has some advantages as a practical battery anode in the aspect of energy efficiency, besides its less capacity and higher equilibrium potential compared with magnesium metal anode. The expanded cyclic voltammogram of the $\mathrm{Mg}_{3} \mathrm{Sb}_{2}$ is also shown in the inset of Figure 2. Reversible current around $-2.05 \mathrm{~V}$ vs. $\mathrm{Ag}^{+} / \mathrm{Ag}$ is observed, and another anodic current appeared at $-1.7 \mathrm{~V}$ vs. $\mathrm{Ag}^{+} / \mathrm{Ag}$ and above. It indicates the $\mathrm{Mg}_{3} \mathrm{Sb}_{2}$ also has some reversibility at slightly higher equilibrium potential of $\mathrm{Mg}_{3} \mathrm{Bi}_{2}$, the observed current is however negligible compared with $\mathrm{Mg}_{3} \mathrm{Bi}_{2}$. We suspect only the surface of the $\mathrm{Mg}_{3} \mathrm{Sb}_{2}$ particle is electrochemically active in the composite electrode.

\section{Electrochemical Properties of the $\mathrm{Mg}_{3} \mathrm{Bi}_{2}$ Thin Film Electrodes}

In order to investigate the correlation between the electrochemical properties of the $\mathrm{Mg}_{3} \mathrm{Bi}_{2}$ and the surface layer, $\mathrm{Mg}_{3} \mathrm{Bi}_{2}$ thin film electrodes were fabricated by magnetron sputtering process. An SEM image and an XRD pattern of the $\mathrm{Mg}_{3} \mathrm{Bi}_{2}$ thin film are shown in Figure 3. The SEM image shows a polycrystalline $\mathrm{Mg}_{3} \mathrm{Bi}_{2}$ thin film having $200-300 \mathrm{~nm}$ of secondary particles. The diffraction pattern of the $\mathrm{Mg}_{3} \mathrm{Bi}_{2}$ thin film well matches with the powder pattern discussed in the previous section. Since the fabrication process does not 
have post annealing process, the $\mathrm{Mg}_{3} \mathrm{Bi}_{2}$ thin film has slightly poor crystallinity. The small peak observed at $22.6^{\circ}$ of $2 \theta$ is corresponding the 003 reflection of the bismuth remained as impurity phase. The peak of 012 reflection of the bismuth, which is the main peak of the powder pattern, is not clearly observed, hence the bismuth impurity phase has a preferred orientation to $\mathrm{c}$-axis to minimize the surface energy during the deposition process.

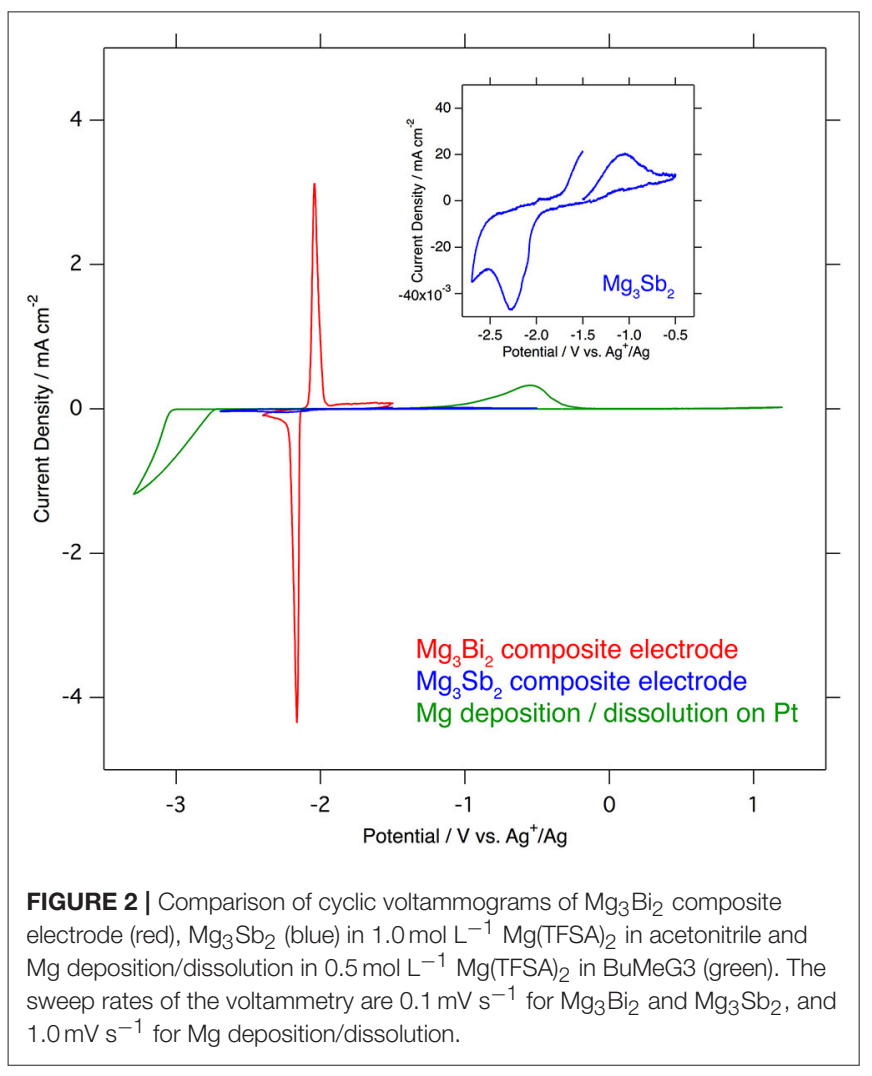

Figure 4 shows cyclic voltammograms of the $\mathrm{Mg}_{3} \mathrm{Bi}_{2}$ thin film electrodes in various electrolyte solutions: $1.0 \mathrm{~mol} \mathrm{\textrm {L } ^ { - 1 }}$ $\mathrm{Mg}(\mathrm{TFSA})_{2}$ in $\mathrm{AN}, 0.5 \mathrm{~mol} \mathrm{~L}^{-1} \mathrm{Mg}(\mathrm{TFSA})_{2}$ in BuMeG3, and $0.5 \mathrm{~mol} \mathrm{~L}^{-1} \mathrm{Mg}$ (TFSA) 2 in dimethoxyethane: G1 (Kishida). The $\mathrm{Mg}_{3} \mathrm{Bi}_{2}$ thin film shows reversible redox reaction in all the three electrolyte solutions. The redox potentials of the $\mathrm{Mg}_{3} \mathrm{Bi}_{2}$ in $0.5 \mathrm{~mol} \mathrm{~L}^{-1} \mathrm{Mg}$ (TFSA $)_{2}$ in BuMeG3 and G1 are -2.3 to $-2.4 \mathrm{~V}$ vs. $\mathrm{Ag}^{+} / \mathrm{Ag}$, lower than the redox potential in $\mathrm{AN}$ electrolyte solution; we suspect it is due to the difference of the $\mathrm{Ag}^{+} / \mathrm{Ag}$ redox potential in the reference electrode corresponding to the solvation properties of $\mathrm{AN}$ and the glymes. The broad peaks of the cyclic voltammogram of the BuMeG3 electrolyte solution indicates that the redox reaction is kinetically slow due to the high viscosity of the solution. The overpotential between the anodic and cathodic reaction is $\sim 100 \mathrm{mV}$, which is slightly higher than that of $\mathrm{AN}$, it is still much lower than the overpotential observed in the deposition/dissolution process of the magnesium metal in these glyme solutions.

\section{Surface Layer of $\mathrm{Mg}_{3} \mathrm{Bi}_{2}$ Thin Film Electrode}

The excellent reversibility of the $\mathrm{Mg}_{3} \mathrm{Bi}_{2}$ thin films in the three electrolyte solutions indicates that the surface of the $\mathrm{Mg}_{3} \mathrm{Bi}_{2}$ electrodes are not passivated in these electrolyte solutions. Thus, we performed XPS analyses of the $\mathrm{Mg}_{3} \mathrm{Bi}_{2}$ and the magnesium metal thin film immersed in the electrolyte solution to confirm the absence of the passivation layer. The BuMeG3 solution was chosen for the surface analysis because we previously observed the formation of $\mathrm{MgF}_{2}$-based passivation layer at the surface of a commercial magnesium foil (Kuwata et al., 2017). Figure 5 shows F1s XPS spectra of the sputtered $\mathrm{Mg}_{3} \mathrm{Bi}_{2}$ and magnesium metal thin films. Despite our expectation, both of the thin films showed similar spectra to that we observed at the surface of the magnesium foil. The spectra have peaks at $688.8 \mathrm{eV}$, corresponding to the residue of the TFSA anion at the surface of the electrodes. The TFSA residue gradually decreased and mostly

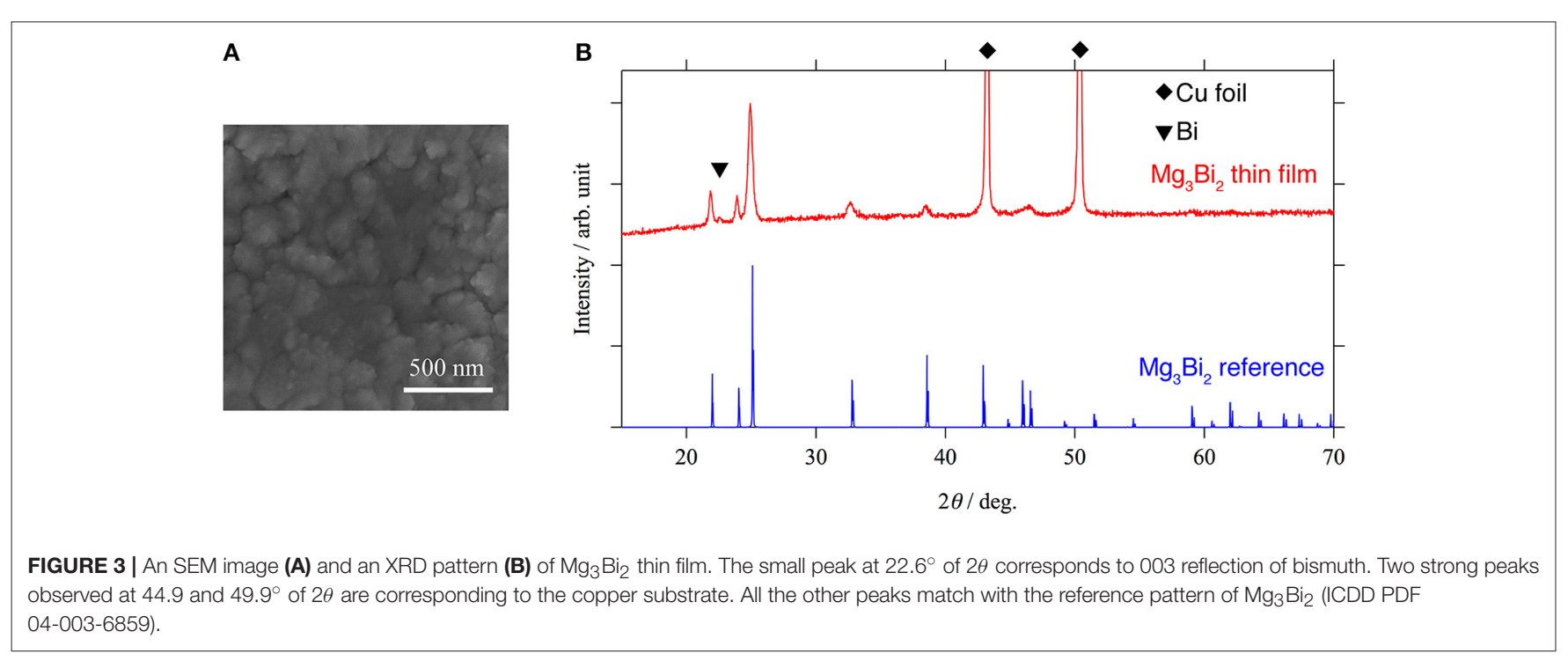



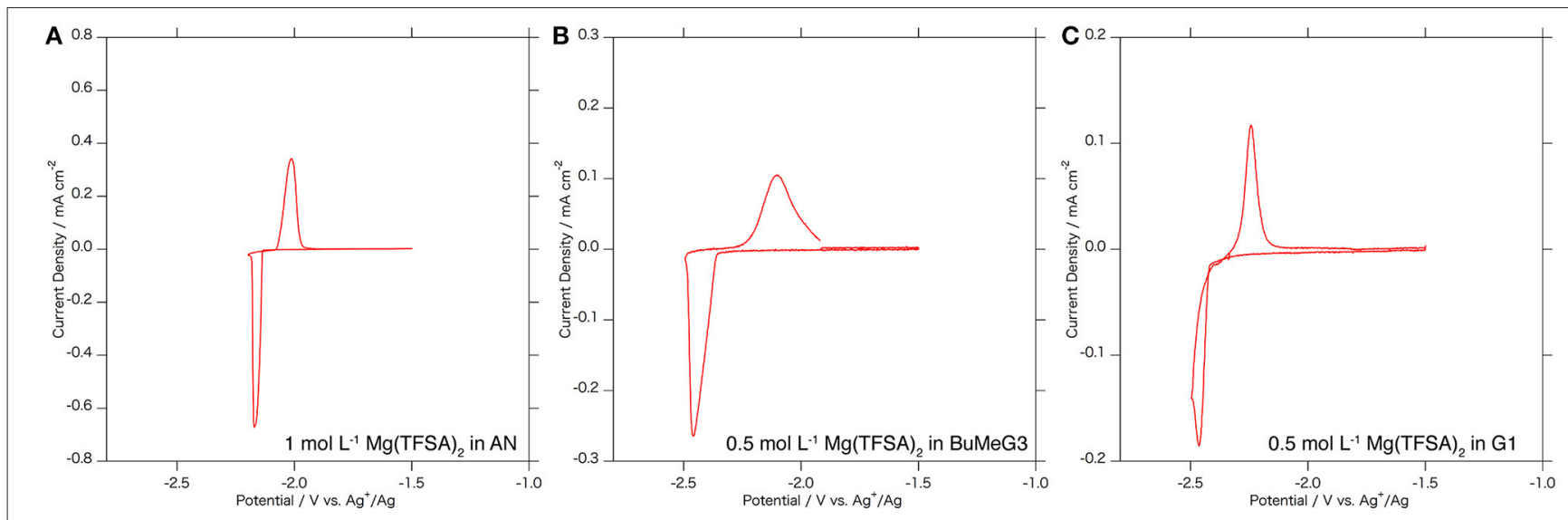

FIGURE 4 | Cyclic voltammograms of the $\mathrm{Mg}_{3} \mathrm{Bi}_{2}$ thin film electrodes in (A) 1 mol $\mathrm{L}^{-1} \mathrm{Mg}(\mathrm{TFSA})_{2}$ in AN solution, (B) $0.5 \mathrm{~mol} \mathrm{L^{-1 }} \mathrm{Mg}(\mathrm{TFSA})_{2}$ in BuMeG3 solution, and (C) $0.5 \mathrm{~mol} \mathrm{~L}^{-1} \mathrm{Mg}(\mathrm{TFSA})_{2}$ in $\mathrm{G} 1$ solution. Reference electrode is a silver wire immersed in $0.01 \mathrm{~mol} \mathrm{~L}^{-1} \mathrm{AgNO}_{3} \mathrm{AN}$ solution for (A) and $0.01 \mathrm{~mol} \mathrm{~L}-1 \mathrm{AgTfO}$ solution in BuMeG3/G1 solutions for (B,C). Counter electrode is Pt foil for (A) and Mg foil for (B,C). The sweep rate of the voltammetry is $0.1 \mathrm{mV} \mathrm{s}^{-1}$.
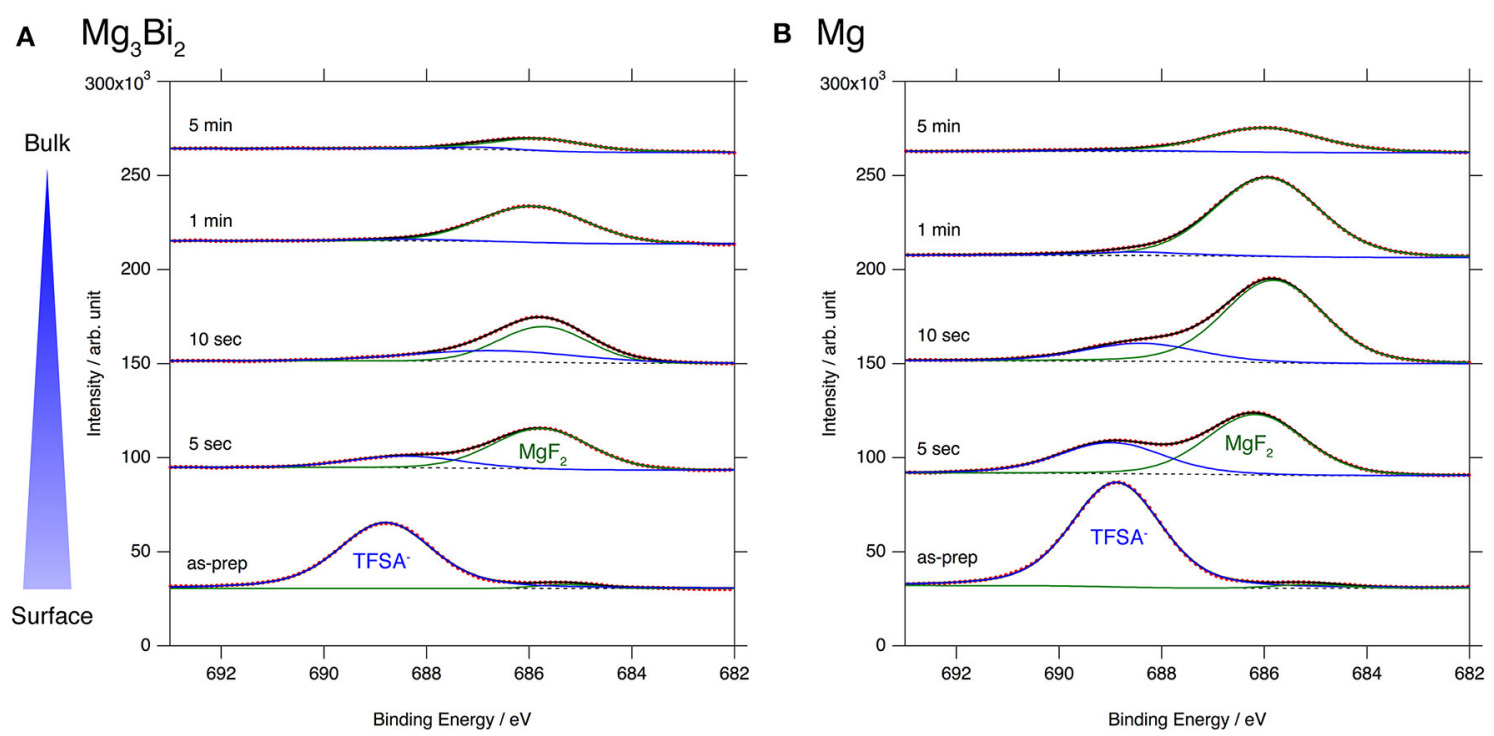

FIGURE 5 | F1s XPS spectra for (A) $\mathrm{Mg}_{3} \mathrm{Bi}_{2}$ thin film and (B) Mg thin film immersed in $0.5 \mathrm{~mol} \mathrm{~L}^{-1} \mathrm{Mg}(\mathrm{TFSA})_{2}$ in BuMeG3 solution for $24 \mathrm{~h}$.

disappeared after 10 seconds of the argon sputtering. Another peak corresponding to the $\mathrm{MgF}_{2}$ simultaneously appeared at $685.7 \mathrm{eV}$ during the further sputtering process. The formation of the $\mathrm{MgF}_{2}$ layer is a direct evidence of the cathodic decomposition of the TFSA anion in the electrolyte solution. Even though the relatively weak peak intensity of the $\mathrm{MgF}_{2}$ on the $\mathrm{Mg}_{3} \mathrm{Bi}_{2}$ suggests the formation of thinner or less dense surface layer, the formation of $\mathrm{MgF}_{2}$ proves that the equilibrium potential of the $\mathrm{Mg}_{3} \mathrm{Bi}_{2}\left(0.28 \mathrm{~V}\right.$ vs. $\left.\mathrm{Mg}^{2+} / \mathrm{Mg}\right)$ is still low enough to reduce the TFSA anion. Figure 6 shows Mg2p spectra of the $\mathrm{Mg}_{3} \mathrm{Bi}_{2}$ and the magnesium metal thin films. Even with the fitting result, the removal of the $\mathrm{MgF}_{2}$ is not clearly confirmed in the Mg2p XPS spectra of the $\mathrm{Mg}_{3} \mathrm{Bi}_{2}$ thin film shown in Figure 6A, because the peak corresponding to the $\mathrm{Mg}_{3} \mathrm{Bi}_{2}$ and the $\mathrm{MgF}_{2}$ are overlapped with each other around $49.8 \mathrm{eV}$. It shows the $\mathrm{Mg}$ atoms in the $\mathrm{Mg}_{3} \mathrm{Bi}_{2}$ phase is positively charged and behave as cations in the solid phase. The Mg2p spectra for the magnesium metal thin film shown in Figure 6B are good reference to understand the structure of the surface layer. A peak corresponding to the magnesium metal appears after 10 seconds of the argon sputtering process at $48.7 \mathrm{eV}$. Then the peak intensity of the magnesium metal gradually increased during the following sputtering process. Since the decrease of the peak intensity of the $\mathrm{MgF}_{2}$ layer is strongly associated with the F1s spectra, we conclude that the main component of the surface layer on these electrodes is $\mathrm{MgF}_{2}$. As already discussed in section Electrochemical properties of the $\mathrm{Mg}_{3} \mathrm{Bi}_{2}$ thin film electrodes, the $\mathrm{Mg}_{3} \mathrm{Bi}_{2}$ thin film electrode shows $100 \mathrm{mV}$ of 

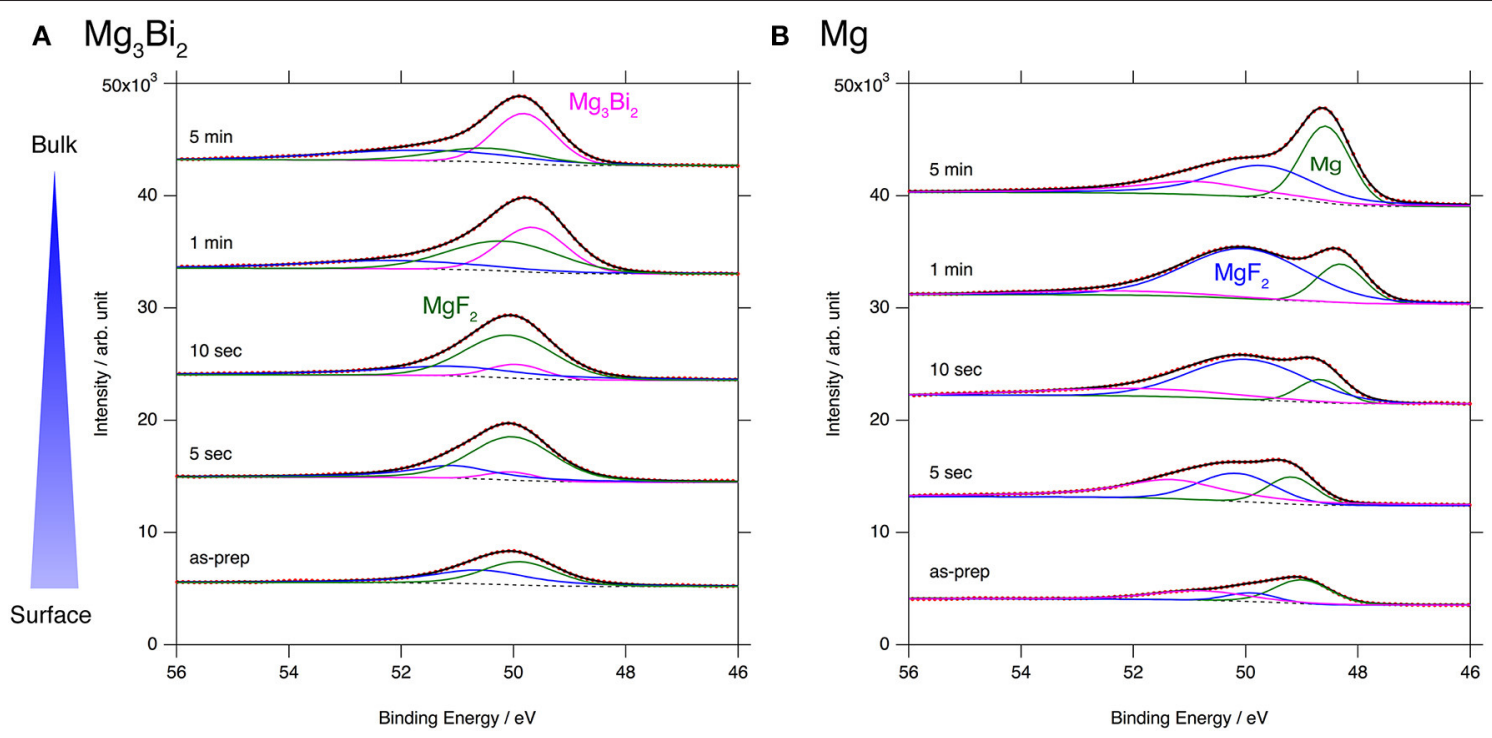

FIGURE 6 | Mg2p XPS spectra for (A) $\mathrm{Mg}_{3} \mathrm{Bi}_{2}$ thin film and (B) Mg thin film immersed in $0.5 \mathrm{~mol} \mathrm{~L}^{-1} \mathrm{Mg}(\mathrm{TFSA})_{2}$ in BuMeG3 solution for $24 \mathrm{~h}$.

overpotential in the BuMeG3 solution, even with the formation of the $\mathrm{MgF}_{2}$ layer. Moreover, the similarity of the surface layer on the $\mathrm{Mg}_{3} \mathrm{Bi}_{2}$ and magnesium metal thin films, suggests that the $\mathrm{MgF}_{2}$ does not completely passivate the surface of the both electrodes. Therefore, we think that the origin of the high overpotential of the magnesium deposition/dissolution process in the glyme-based electrolyte solution is not the resistance of the surface layer, but the activation energy of the actual electrode reaction process, which consists of several reaction steps such as adsorption of $\mathrm{Mg}^{2+}$ ions, desolvation, electrontransfer, surface, and bulk diffusion of $\mathrm{Mg}$ atoms and so forth. Among these reaction steps, we speculate the electron-transfer process significantly contributes to the overpotential, because the biggest difference of the electrode reactions between the $\mathrm{Mg}_{3} \mathrm{Bi}_{2}$ and the magnesium metal, is the oxidation state of the $\mathrm{Mg}^{2+}$ ions. As presented in the Mg2p XPS spectra in Figure 6A, the $\mathrm{Mg}^{2+}$ ions in the electrolyte solution are not reduced to the $\mathrm{Mg}$ atoms in the case of $\mathrm{Mg}_{3} \mathrm{Bi}_{2}$, on the other hand, the $\mathrm{Mg}^{2+}$ ions are reduced to the magnesium metal during the electrodeposition process. Further analytical studies are necessary to be conducted to determine the origin of the overpotential.

\section{Stability Test of the $\mathbf{M g}_{3} \mathrm{Bi}_{2}$ and $\mathbf{M g}_{3} \mathrm{Sb}_{2}$}

Since the XPS results only provide the composition and the oxidation state of the elements, here we investigated the stability of the passivation layer on the $\mathrm{Mg}_{3} \mathrm{Bi}_{2}$ and the $\mathrm{Mg}_{3} \mathrm{Sb}_{2}$ by storing them in ambient atmosphere and water. The XRD patterns of the $\mathrm{Mg}_{3} \mathrm{Bi}_{2}$ and $\mathrm{Mg}_{3} \mathrm{Sb}_{2}$ do not show any changes during the initial $24 \mathrm{~h}$ storage in air as shown in Figures 7A,B. It indicates the surfaces of the particles were well passivated. Subsequently we added $0.05 \mathrm{ml}$ of water per sample holder, containing $\sim 0.5 \mathrm{~g}$ of the powder sample. Immediately a new peak corresponding to the 012 reflection of bismuth appeared at $27.4^{\circ}$ of $2 \theta$ as shown in Figure 7A. Though no diffraction peaks corresponding to $\mathrm{Mg}(\mathrm{OH})_{2}$ are observed, the formation of the bismuth suggests the hydrolysis of the $\mathrm{Mg}_{3} \mathrm{Bi}_{2}$ in the following Equation (1).

$$
\mathrm{Mg}_{3} \mathrm{Bi}_{2}+6 \mathrm{H}_{2} \mathrm{O} \longrightarrow 3 \mathrm{Mg}(\mathrm{OH})_{2}+2 \mathrm{Bi}+3 \mathrm{H}_{2} \uparrow
$$

We think the missing of the $\mathrm{Mg}(\mathrm{OH})_{2}$ is due to the poor crystallinity, because the hydrolysis occurred at room temperature. Furthermore, the hydrolysis also indicates no passivation layer formation at the surface of the $\mathrm{Mg}_{3} \mathrm{Bi}_{2}$. Even though the experimental protocol is not qualified to have quantitative discussions for the reaction kinetics, we think the hydrolysis is a good evidence to prove the passivationfree surface of the $\mathrm{Mg}_{3} \mathrm{Bi}_{2}$. On the other hand, the $\mathrm{Mg}_{3} \mathrm{Sb}_{2}$ never shows any hydrolysis even $72 \mathrm{~h}$ after the addition of the water, as if the surface of the $\mathrm{Mg}_{3} \mathrm{Sb}_{2}$ is well-passivated. However, there still remains a question whether the stability is really owing to the passivation layer or the stability of the bulk $\mathrm{Mg}_{3} \mathrm{Sb}_{2}$ phase, considering the chemical similarity between bismuth and antimony. Hence we attempted further acceleration of the hydrolysis by immersing the $\mathrm{Mg}_{3} \mathrm{Bi}_{2}$ and the $\mathrm{Mg}_{3} \mathrm{Sb}_{2}$ powders in excess amount of water. The formation of the $\mathrm{Sb}$ is slightly observed after $24 \mathrm{~h}$ storage in excess water, and we finally observed the clear evidence of the hydrolysis of the $\mathrm{Mg}_{3} \mathrm{Sb}_{2}$ after 10 days, as shown in Figure 7C. The $\mathrm{Mg}_{3} \mathrm{Bi}_{2}$ obviously showed much faster hydrolysis compared with the $\mathrm{Mg}_{3} \mathrm{Sb}_{2}$ and the hydrolysis is almost completed after 6 days storage. The hydrolysis of the $\mathrm{Mg}_{3} \mathrm{Bi}_{2}$ and the $\mathrm{Mg}_{3} \mathrm{Sb}_{2}$ proves that the formation of the thermodynamically stable intermetallic phase suppress the formation of the passivation layer. As a consequence, an electrochemically active electrode/electrolyte interphase is maintained. We also attribute that the electrochemical activity of the intermetallic anode 
is highly dependent upon the reaction kinetics, because the hydrolysis of the intermetallics is fundamentally same as the electrochemical reaction. In the hydrolysis process of the intermetallic anodes, the reduction of the proton in the water initiates the oxidation of the $\mathrm{Mg}_{3} \mathrm{Bi}_{2}$ or the $\mathrm{Mg}_{3} \mathrm{Sb}_{2}$ associated with the extraction of $\mathrm{Mg}^{2+}$ in the host structure. The $\mathrm{Mg}_{3} \mathrm{Sb}_{2}$ still remains even after the 10 days of the reaction, while the hydrolysis of the $\mathrm{Mg}_{3} \mathrm{Bi}_{2}$ is mostly completed after $<6$ days as shown in Figure 7C. It clearly shows the reaction kinetics of the hydrolysis process of the $\mathrm{Mg}_{3} \mathrm{Bi}_{2}$ is much faster than that of the $\mathrm{Mg}_{3} \mathrm{Sb}_{2}$. Even without the quantitative discussion, the fast reaction kinetics of the hydrolysis process well matches with the electrochemical activity of the intermetallic anodes.
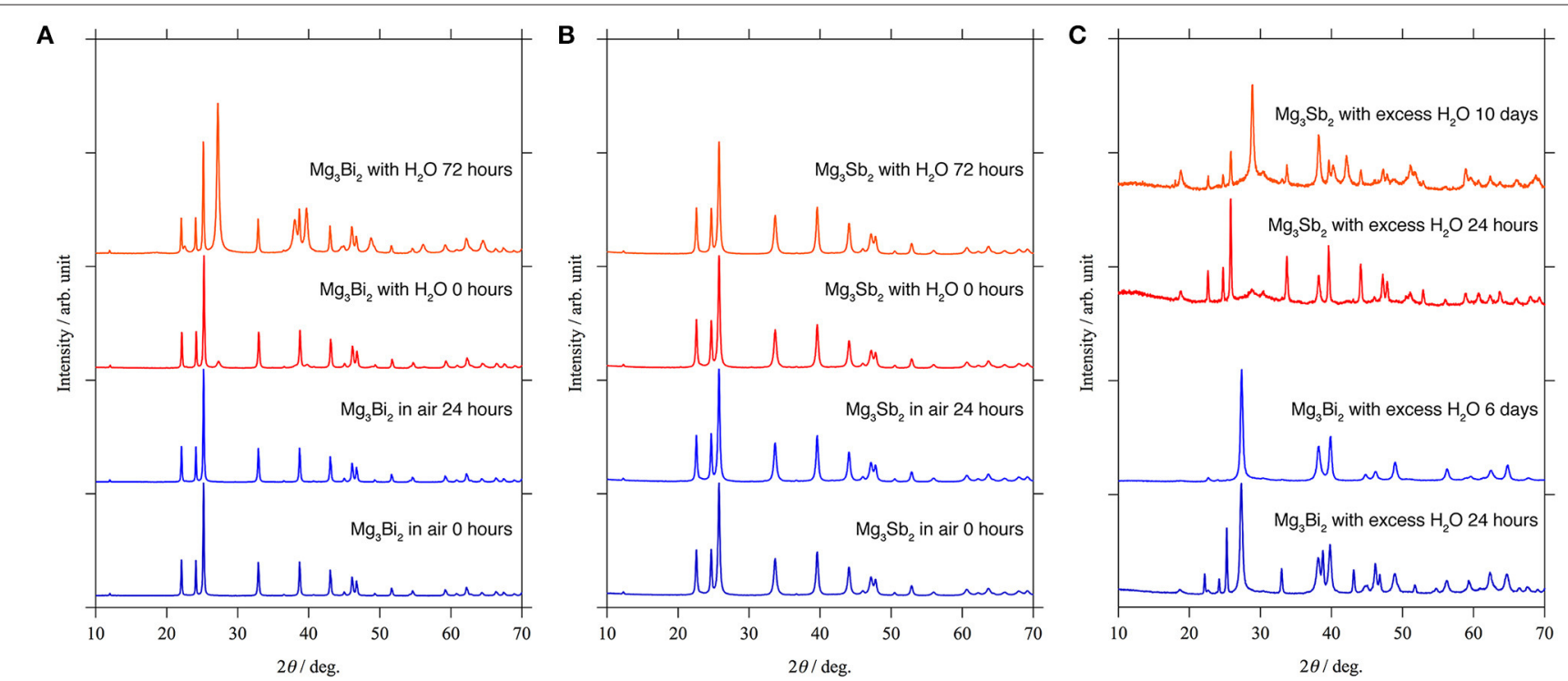

FIGURE 7 |XRD patterns for the stability test: (A) $\mathrm{Mg}_{3} \mathrm{Bi}_{2}$ and (B) $\mathrm{Mg}_{3} \mathrm{Sb}_{2}$ powder in ambient atmosphere and small amount of water. (C) $\mathrm{Mg}_{3} \mathrm{Bi}_{2}$ powder and $\mathrm{Mg}_{3} \mathrm{Sb}_{2}$ powder immersed in the excess amount of water.
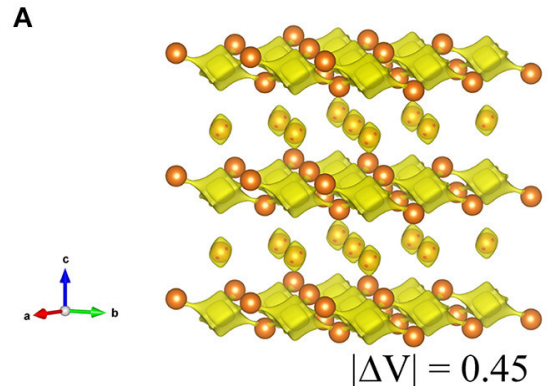

D

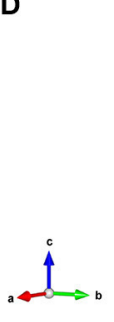

B

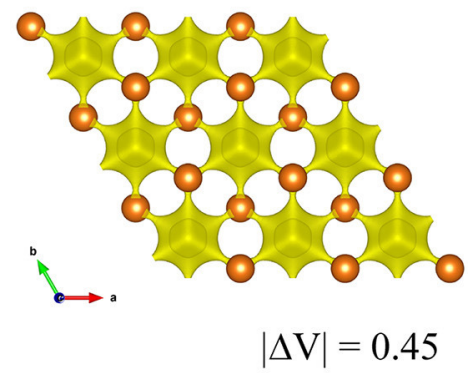

E

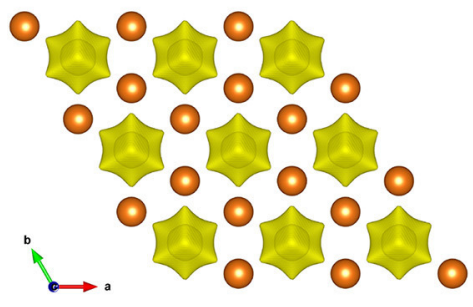

$|\Delta \mathrm{V}|=0.45$
C

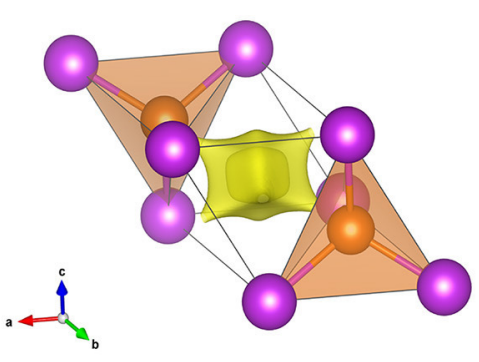

$\mathbf{F}$

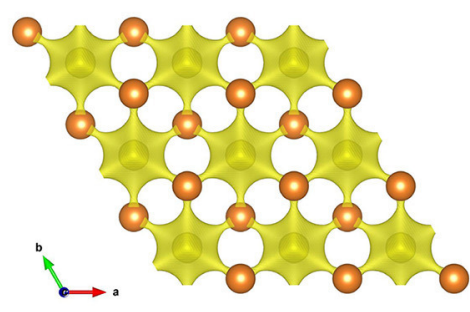

$|\Delta \mathrm{V}|=0.6$

FIGURE 8 | Visualized $\mathrm{Mg}^{2+}$ diffusion pathways by BVS mapping in $\mathrm{Mg}_{3} \mathrm{Bi}_{2}$ and $\mathrm{Mg}_{3} \mathrm{Sb}_{2}$. (A) overview of $\mathrm{Mg}_{3} \mathrm{Bi}_{2}$, (B) the $2 \mathrm{D}$ diffusion pathways in $2 d$ tetrahedral sites in $\mathrm{Mg}_{3} \mathrm{Bi}_{2}$ from c-axis, and (C) an enlarged image of two $\mathrm{MgBi}_{4}$ tetrahedra with an interstitial octahedron, (D) overview of $\mathrm{Mg}_{3} \mathrm{Sb}_{2}$, (E) $2 d$ tetrahedral sites in $\mathrm{Mg}_{3} \mathrm{Sb}_{2}$ from c-axis (F) $2 d$ tetrahedral sites in $\mathrm{Mg}_{3} \mathrm{Sb}_{2}$ from c-axis at cut off $|\Delta \mathrm{V}|=0.6$. 


\section{$\mathbf{M g}^{2+}$ Diffusion Pathways in the $\mathbf{M g}_{3} \mathrm{Bi}_{2}$}

The $\mathrm{Mg}^{2+}$ diffusion in the bulk active materials is one of the key parameters which determines the reaction kinetics of the magnetization/demagnetization process, here we investigated the diffusion pathways of $\mathrm{Mg}^{2+}$ in the $\mathrm{Mg}_{3} \mathrm{Bi}_{2}$ and the $\mathrm{Mg}_{3} \mathrm{Sb}_{2}$. The bond valence sum (BVS) mapping is one methodology to visualize the pathways of the mobile ions in the crystal structure. The bond-valence parameters for $\mathrm{Mg}_{3} \mathrm{Bi}_{2}$ and $\mathrm{Mg}_{3} \mathrm{Sb}_{2}$ were calculated by following equation (Brese and O'Keeffe, 1991).

$$
R o=b \ln \left[V_{i j} / \Sigma_{j} \exp \left(-d_{i j} / b\right)\right]
$$

Here $b$ is commonly taken to a constant value $0.37 \AA . V_{i j}$ is sum of valences of given atoms $i$ and $d_{i j}$ is bond length from refinement results. The calculated $R o$ value for the $\mathrm{Mg}_{3} \mathrm{Bi}_{2}$ and the $\mathrm{Mg}_{3} \mathrm{Sb}_{2}$ are 2.687 and 2.617, respectively. Figure 8 shows the BVS mapping of the $\mathrm{Mg}_{3} \mathrm{Bi}_{2}$ and the $\mathrm{Mg}_{3} \mathrm{Sb}_{2}$ using the refined structure model with discussed in Electrochemical properties of the $\mathrm{Mg}_{3} \mathrm{Bi}_{2}$ and $\mathrm{Mg}_{3} \mathrm{Sb}_{2}$ composite electrode. The BVS mappings of the $\mathrm{Mg}_{3} \mathrm{Bi}_{2}$ clearly show $2 \mathrm{D}$ layered diffusion pathways connecting the $2 d$ tetrahedral sites at cut off value: $|\Delta \mathrm{V}|$ $=0.45$ as shown in Figures 8A,B. Figure 8C shows a migration path between the two tetrahedral sites of the $\mathrm{Mg}_{3} \mathrm{Bi}_{2}$. The $\mathrm{Mg}^{2+}$ ion at the tetrahedral site is preferred to migrate to the next tetrahedral site, via the interstitial octahedral site. The estimated migration path is in good agreement with the proposed diffusion path model for $\mathrm{Mg}^{2+}$ by DFT-NEB simulations (Rong et al., 2015). Jung et al. also reported that the migration barrier in between two tetrahedral sites of $\mathrm{Mg}_{3} \mathrm{Bi}_{2}$ is $0.30 \mathrm{eV}$, suggesting fast $\mathrm{Mg}^{2+}$ mobility in the $\mathrm{Mg}_{3} \mathrm{Bi}_{2}$ phase (Jung and Han, 2018). In addition, once the vacancy is formed, the fast migration of the $\mathrm{Mg}^{2+}$ from the octahedral site to the vacancy at the tetrahedral site is also expected (Lee et al., 2018). Even though the BVS mapping is not as accurate as DFT modeling, the estimated $\mathrm{Mg}^{2+}$ diffusion pathways are qualitatively informative to discuss the fast $\mathrm{Mg}^{2+}$ mobility in the solid phase. We also performed the BVS mapping of the $\mathrm{Mg}_{3} \mathrm{Sb}_{2}$ as shown in Figures 8D,E. At glance, the estimated diffusion pathways look similar to the mapping of the $\mathrm{Mg}_{3} \mathrm{Bi}_{2}$, however all the preferred diffusion path at interstitial octahedral sites are isolated at cut off value: $|\Delta V|=0.45$, as seen in Figure 8E. Figure 8F shows the 2D layered diffusion pathways in the $\mathrm{Mg}_{3} \mathrm{Sb}_{2}$ formed at cut off value: $|\Delta \mathrm{V}|=0.6$. The higher cut off value indicates that the higher migration barrier of the $\mathrm{Mg}^{2+}$ ions in the $\mathrm{Mg}_{3} \mathrm{Sb}_{2}$ (Fedotov et al., 2018). The BVS mapping results suggests that the $\mathrm{Mg}^{2+}$ migration in $\mathrm{Mg}_{3} \mathrm{Bi}_{2}$ is qualitatively faster than in $\mathrm{Mg}_{3} \mathrm{Sb}_{2}$. Though we still need further validation analyses, all the results are consistent with the contribution of the fast $\mathrm{Mg}^{2+}$ mobility to the excellent electrochemical properties of the $\mathrm{Mg}_{3} \mathrm{Bi}_{2}$.

\section{CONCLUSION}

In the present study, we investigated the electrochemical properties of the magnesium-based intermetallic compounds as alternative anode active material for magnesium batteries. Even though the $\mathrm{Mg}_{3} \mathrm{Bi}_{2}$ and the $\mathrm{Mg}_{3} \mathrm{Sb}_{2}$ have same crystal structure, the electrochemical activity of the $\mathrm{Mg}_{3} \mathrm{Sb}_{2}$ was almost negligible, while the $\mathrm{Mg}_{3} \mathrm{Bi}_{2}$ showed highly reversible redox reaction at $-2.1 \mathrm{~V}$ vs. $\mathrm{Ag}^{+} / \mathrm{Ag}$. The XPS analyses of the $\mathrm{Mg}_{3} \mathrm{Bi}_{2}$ thin films showed formations of the $\mathrm{MgF}_{2}$-based surface layer, which is the reduction product of the TFSA anion and also observed at the surface of the magnesium metal thin film. On the other hand, the excellent electrochemical activity of $\mathrm{Mg}_{3} \mathrm{Bi}_{2}$ in three electrolyte solutions: $1 \mathrm{~mol} \mathrm{~L}^{-1} \mathrm{Mg}(\mathrm{TFSA})_{2}$ in $\mathrm{AN}, 0.5 \mathrm{~mol} \mathrm{~L}^{-1} \mathrm{Mg}(\mathrm{TFSA})_{2}$ in BuMeG3 , and $0.5 \mathrm{~mol} \mathrm{~L}^{-1}$ $\mathrm{Mg}(\mathrm{TFSA})_{2}$ in DME, suggests that the surface of the $\mathrm{Mg}_{3} \mathrm{Bi}_{2}$ is not passivated even with the formation of the $\mathrm{MgF}_{2}$ layer. We also investigated the stability of the $\mathrm{Mg}_{3} \mathrm{Bi}_{2}$ and the $\mathrm{Mg}_{3} \mathrm{Sb}_{2}$ in ambient atmosphere and in water. The stability tests of the intermetallics revealed that the formation of the intermetallics is an effective way to avoid the passivation of the anode surface. The results also suggested the reversibility of the intermetallic anode is not only dependent on the passivation-free surface, but on the fast reaction kinetics. The BVS mapping showed that the $\mathrm{Mg}^{2+}$ conduction pathway among tetrahedral sites well matches with the predicted fast $\mathrm{Mg}^{2+}$ diffusion path by DFT modeling. Here we conclude that the formation of the intermetallics is effective strategy to avoid the passivation of anode surface, which hinders the reversible redox reaction. The fast $\mathrm{Mg}^{2+}$ ion mobility in the solid phase is another key parameter to obtain the good reversibility applicable to a practical battery system.

\section{AUTHOR CONTRIBUTIONS}

$\mathrm{MaM}$ and $\mathrm{HK}$ designed the research approach and experiments. HK carried out the synthesis work. MaM, HK, and DM carried out the structural analyses and the surface analyses. $\mathrm{HK}, \mathrm{NI}$, and MiM carried out the electrochemical analyses. $\mathrm{MaM}$ wrote the manuscript and all authors discussed the final manuscript.

\section{FUNDING}

The present work was financially supported by Japan Science and Technology Agency PRESTO (Grant No. JPMJPR13CA) and Advanced Low Carbon Technology Research and Development Program Specially Promoted Research for Innovative Next Generation Batteries (ALCA-SPRING).

\section{ACKNOWLEDGMENTS}

Many discussions with K. Hanamura, K. Hashimoto, K. Uosaki, K. Kanamura, Y. Tateyama are gratefully acknowledged. We thank to T. Ichikawa for his support in the development of experimental tools. F. Izumi and S. Nishimura kindly advised us for the usage of the crystal structure analyses software. 


\section{REFERENCES}

Adams, S. (2006). From bond valence maps to energy landscapes for mobile ions in ion-conducting solids. Solid State Ionics 177, 1625-1630. doi: 10.1016/j.ssi.2006.03.054

Ahmadpour, F., Kolodiazhnyi, T., and Mozharivskyj, Y. (2007). Structural and physical properties of Mg3-xZnxSb2 $(\mathrm{x}=0-1.34)$. J. Solid State Chem. 180, 2420-2428. doi: 10.1016/j.jssc.2007.06.011

Arthur, T. S., Singh, N., and Matsui, M. (2012). Electrodeposited Bi, Sb and Bi1xSbx alloys as anodes for Mg-ion batteries. Electrochem. Commun. 16, 103-106. doi: 10.1016/j.elecom.2011.12.010

Aurbach, D., Lu, Z., Schechter, A., Gofer, Y., Gizbar, H., Turgeman, R., et al. (2000). Prototype systems for rechargeable magnesium batteries. Nature 407, 724-727. doi: $10.1038 / 35037553$

Aurbach, D., Suresh, G. S., Levi, E., Mitelman, A., Mizrahi, O., Chusid, O., et al. (2007). Progress in rechargeable magnesium battery technology. Adv. Mater. 19, 4260-4267. doi: 10.1002/adma.200701495

Aurbach, D., Weissman, I., Gofer, Y., and Levi, E. (2003). Nonaqueous magnesium electrochemistry and its application in secondary batteries. Chem. Rec. 3, 61-73. doi: 10.1002/tcr.10051

Brese, N. E., and O'Keeffe, M. (1991). Bond-valence parameters for solids. Acta Crystallogr. Section B 47, 192-197. doi: 10.1107/S0108768190011041

Fedotov, S. S., Kabanova, N. A., Kabanov, A. A., Blatov, V. A., Khasanova, N. R., and Antipov, E. V. (2018). Crystallochemical tools in the search for cathode materials of rechargeable Na-ion batteries and analysis of their transport properties. Solid State Ionics 314, 129-140. doi: 10.1016/j.ssi.2017.11.008

Izumi, F., and Momma, K. (2007). Three-dimensional visualization in powder diffraction. Solid State Phenomena 130, 15-20. doi: 10.4028/www.scientific.net/SSP.130.15

Jung, S. C., and Han, Y.-K. (2018). Fast magnesium ion transport in the Bi/Mg3Bi2 two-phase electrode. J. Phys. Chem. C 122, 17643-17649. doi: 10.1021/acs.jpcc.8b02840

Kuwata, H., Matsui, M., and Imanishi, N. (2017). Passivation layer formation of magnesium metal negative electrodes for rechargeable magnesium batteries. J. Electrochem. Soc. 164, A3229-A3236. doi: 10.1149/2.1191713jes

Larcher, D., and Tarascon, J. M. (2015). Towards greener and more sustainable batteries for electrical energy storage. Nat. Chem. 7, 19-29. doi: $10.1038 /$ nchem.2085

Lee, J., Monserrat, B., Seymour, I. D., Liu, Z., Dutton, S. E., and Grey, C. P. (2018). An ab initio investigation on the electronic structure, defect energetics, and magnesium kinetics in $\mathrm{Mg}_{3} \mathrm{Bi}_{2}$. J. Mater. Chem. A 6, 16983-16991. doi: 10.1039/C7TA11181A

Lin, D., Liu, Y., and Cui, Y. (2017). Reviving the lithium metal anode for highenergy batteries. Nat. Nanotechnol. 12, 194-206. doi: 10.1038/nnano.2017.16
Liu, Z., Lee, J., Xiang, G., Glass, H. F., Keyzer, E. N., Dutton, S. E., et al. (2017). Insights into the electrochemical performances of $\mathrm{Bi}$ anodes for $\mathrm{Mg}$ ion batteries using $25 \mathrm{Mg}$ solid state NMR spectroscopy. Chem. Commun. 53, 743-746. doi: 10.1039/C6CC08430C

Lu, Z., Schechter, A., Moshkovich, M., and Aurbach, D. (1999). On the electrochemical behavior of magnesium electrodes in polar aprotic electrolyte solutions. J. Electroanal. Chem. 466, 203-217. doi: 10.1016/S0022-0728(99)00146-1

Matsui, M. (2011). Study on electrochemically deposited Mg metal. J. Power Sources 196, 7048-7055. doi: 10.1016/j.jpowsour.2010.11.141

Momma, K., and Izumi, F. (2011). VESTA 3 for three-dimensional visualization of crystal, volumetric and morphology data. J. Appl. Crystallogr. 44, 1272-1276. doi: $10.1107 /$ S0021889811038970

Muldoon, J., Bucur, C. B., Oliver, A. G., Sugimoto, T., Matsui, M., Kim, H. S., et al. (2012). Electrolyte roadblocks to a magnesium rechargeable battery. Energy Environ. Sci. 5, 5941-5950. doi: 10.1039/c2ee03029b

Nishimura, S. (2017). PyAbstantia 0.7. Available online at: https:// shinichinishimura.github.io/pyabst/

Rong, Z., Malik, R., Canepa, P., Sai Gautam, G., Liu, M., Jain, A., et al. (2015). Materials design rules for multivalent ion mobility in intercalation structures. Chem. Mater. 27, 6016-6021. doi: 10.1021/acs.chemmater.5b02342

Singh, N., Arthur, T. S., Ling, C., Matsui, M., and Mizuno, F. (2013). A high energydensity tin anode for rechargeable magnesium-ion batteries. Chem. Commun. 49, 149-151. doi: 10.1039/c2cc34673g

Tutusaus, O., Mohtadi, R., Arthur, T. S., Mizuno, F., Nelson, E. G., and Sevryugina, Y. V. (2015). An efficient halogen-free electrolyte for use in rechargeable magnesium batteries. Angew. Chem. Int. Ed. 54, 7900-7904. doi: 10.1002/anie.201412202

Zhao-Karger, Z., Gil Bardaji, M. E., Fuhr, O., and Fichtner, M. (2017). A new class of non-corrosive, highly efficient electrolytes for rechargeable magnesium batteries. J. Mater. Chem. A 5, 10815-10820. doi: 10.1039/C7TA0 $2237 \mathrm{~A}$

Conflict of Interest Statement: The authors declare that the research was conducted in the absence of any commercial or financial relationships that could be construed as a potential conflict of interest.

Copyright (c) 2019 Matsui, Kuwata, Mori, Imanishi and Mizuhata. This is an openaccess article distributed under the terms of the Creative Commons Attribution License (CC BY). The use, distribution or reproduction in other forums is permitted, provided the original author(s) and the copyright owner(s) are credited and that the original publication in this journal is cited, in accordance with accepted academic practice. No use, distribution or reproduction is permitted which does not comply with these terms. 